\title{
The novel functions of kinesin motor proteins in plants
}

\author{
Juan Li $\cdot$ Yunyuan Xu $\cdot$ Kang Chong
}

Received: 21 October 2011 / Accepted: 28 November 2011 /Published online: 14 December 2011

(C) The Author(s) 2011. This article is published with open access at Springerlink.com

\begin{abstract}
Kinesin superfamily proteins are important microtubule-based motor proteins with a kinesin motor domain that is conserved among all eukaryotic organisms. They are responsible for unidirectionally transporting various cargos, including membranous organelles, protein complexes, and mRNAs. They also play critical roles in mitosis, morphogenesis, and signal transduction. Most kinesins in plants are evolutionarily divergent from their counterparts in animals and fungi. The mitotic kinesins in the plant kinesin- 5 and kinesin-14 subfamilies appear to be similar to those in fungi and animals. However, others with nonmotor sequences are unique to plants. The kinesins affect microtubule organization, organelle distribution, vesicle transport, and cellulose microfibril order. Ultimately, plant kinesins contribute directly or indirectly to cell division and cell growth in various tissues. Here, we review a novel function of kinesins with transcription activation activity in regulating gibberellin biosynthesis and cell growth. These findings will open exciting new areas of kinesin research.
\end{abstract}

Keywords Kinesin · Transcription factor · Cell elongation . Mitosis · Gibberellin synthesis · Rice

\section{Introduction}

Kinesins are a superfamily of microtubule motor proteins ubiquitous in all eukaryotic organisms. The budding yeast

Handling Editor: Peter Nick

J. Li $\cdot$ Y. Xu $\cdot$ K. Chong $(\bowtie)$

Research Center for Molecular and Developmental Biology, Key Laboratory of Photosynthesis and Environmental Molecular Physiology, Institute of Botany, Chinese Academy of Sciences, Beijing 100093, China

e-mail: chongk@ibcas.ac.cn
Saccharomyces cerevisiae has the fewest kinesin genes, 6, and flowering plants have the most: 61 in Arabidopsis and 41 in rice (Reddy and Day 2001; Vale 2003; Richardson et al. 2006). Kinesins function in the unidirectional transport of vesicles and organelles, cytokinesis, signal transduction, and morphogenesis (Reddy and Day 2001; Verhey et al. 2001; Lee and Liu 2004; Hirokawa et al. 2009). Different kinesins have multifaceted roles during mitosis: centrosome separation, chromosome attachment to microtubules, chromosome aggregation to the metaphase plate, sister chromatid segregation, maintenance of bipolar spindle, and spindle elongation (Sharp et al. 2000). All these functions, in unidirectional transport of cell growth or cell mitosis, are mainly based on the relation of kinesins to cytoskeleton microtubules. Two kinesins have been found with novel functions: OsKCH1 simultaneously binds to actin filaments and controls nuclear positioning and the onset of mitosis (Frey et al. 2009, 2010), and OsGDD1 has transcription factor activity that controls gibberellic acid (GA) biosynthesis and cell elongation ( $\mathrm{Li}$ et al. 2011).

\section{Plant kinesins are essential for cell division and growth}

Many plant kinesins are involved in cell division, including mitosis, as well as meiosis (Table 1). In Arabidopsis, AtKRP $125 \mathrm{c}$ of the kinesin-5 family can decorate microtubules throughout the cell cycle and appears to function in both interphase and mitosis (Bannigan et al. 2007). AtNACK1 and AtNACK2, the members of the kinesin-7 family, are essential for the completion of cell-plate formation and tetrad formation during male gametogenesis, respectively (Nishihama et al. 2002; Strompen et al. 2002; Yang et al. 2003). Mutation of OsNACK1 causes severe dwarfism in rice and exhibits cell wall stubs in rapidly dividing cells, reflecting 
Table 1 Kinesin family proteins in plants

\begin{tabular}{|c|c|c|c|c|}
\hline No. & Proteins & Family & Reported function & Reference \\
\hline 1 & OsPSS1 & Kinesin-1 & $\begin{array}{l}\text { Male meiotic chromosomal dynamics, } \\
\text { male gametogenesis, and anther dehiscence }\end{array}$ & Zhou et al. (2011) \\
\hline 2 & AtFRA1 & Kinesin-4 & Microtubule control of cellulose microfibril order & Zhong et al. (2002) \\
\hline 3 & OsBC12/GDD1 & Kinesin-4 & Cell cycle, regulation of gibberellin synthesis & $\begin{array}{l}\text { Zhang et al. (2010); } \\
\text { Li et al. (2011) }\end{array}$ \\
\hline 4 & AtKRP125c & Kinesin-5 & Mitosis & Bannigan et al. (2007) \\
\hline 5 & AtNACK1 & Kinesin-7 & Cytokinesis & $\begin{array}{l}\text { Nishihama et al. (2002); } \\
\text { Strompen et al. (2002) }\end{array}$ \\
\hline 6 & AtNACK2 & Kinesin-7 & Tetrad formation & $\begin{array}{l}\text { Nishihama et al. (2002); } \\
\text { Yang et al. (2003) }\end{array}$ \\
\hline 7 & OsNACK1 & Kinesin-7 & Cytokinesis & Sazuka et al. (2005) \\
\hline 8 & AtKinesin-12A & Kinesin-12 & Phragmoplast microtubule organization & Lee et al. (2007) \\
\hline 9 & AtKinesin-12B & Kinesin-12 & Phragmoplast microtubule organization & Lee et al. (2007) \\
\hline 10 & OsKinesin-12A & Kinesin-12 & Unknown & Guo et al. (2009) \\
\hline 11 & AtKinesin-13A & Kinesin-13 & $\begin{array}{l}\text { Trichome morphogenesis, formation of } \\
\text { Golgi vesicles }\end{array}$ & $\begin{array}{l}\text { Lu et al. (2005); } \\
\text { Wei et al. (2009) }\end{array}$ \\
\hline 12 & AtKinesin-13B & Kinesin-13 & Trichome morphogenesis & Lu et al. (2005) \\
\hline 13 & GhKinesin-13A & Kinesin-13 & Associated with Golgi stacks & Lu et al. (2005) \\
\hline 14 & OsSRS3 & Kinesin-13 & Cell length of seeds & Kitagawa et al. (2010) \\
\hline 15 & AtKATA/ATK1 & Kinesin-14 & Chromosome segregation, spindle assembly & $\begin{array}{l}\text { Chen et al. (2002); } \\
\text { Marcus et al. (2003) }\end{array}$ \\
\hline 16 & $\begin{array}{l}\text { AtKAC } 1 / \mathrm{KLP} 2 / \mathrm{KCA} 1 / \\
\text { GRIMP/KSN1 }\end{array}$ & Kinesin-14 & Actin-based chloroplast movement & $\begin{array}{l}\text { Vanstraelen et al. (2004); } \\
\text { Geelen and Inze (2001); } \\
\text { Kong et al. (2002); } \\
\text { Bouquin et al. (2003); } \\
\text { Suetsugu et al. (2010) }\end{array}$ \\
\hline 17 & AtKAC2/KCA2 & Kinesin-14 & Actin-based chloroplast movement & $\begin{array}{l}\text { Vanstraelen et al. (2004); } \\
\text { Suetsugu et al. (2010) }\end{array}$ \\
\hline 18 & AtKCBP & Kinesin-14 & $\begin{array}{l}\text { Microtubule organization/stability, } \\
\text { trichome morphogenesis }\end{array}$ & $\begin{array}{l}\text { Reddy et al. (1996); } \\
\text { Song et al. (1997); } \\
\text { Day et al. (2000) }\end{array}$ \\
\hline 19 & TvKCBP & Kinesin-14 & Cell division & Vos et al. (2000) \\
\hline 20 & GhKCBP & Kinesin-14 & Cell division & Preuss et al. (2003) \\
\hline 21 & AtKP1 & Kinesin-14 & $\begin{array}{l}\text { Regulation of respiration during seed germination } \\
\text { at low temperature }\end{array}$ & $\begin{array}{l}\text { Ni et al. (2005); } \\
\text { Yang et al. (2011) }\end{array}$ \\
\hline 22 & GhKCH1 & Kinesin-14 & Dynamic microtubule-microfilament cross-linking & Preuss et al. (2004) \\
\hline 23 & GhKCH2 & Kinesin-14 & Dynamic microtubule-microfilament cross-linking & Xu et al. (2009) \\
\hline 24 & OsKCH1 & Kinesin-14 & $\begin{array}{l}\text { Linkers between actin filaments and microtubules } \\
\text { during nuclear positioning }\end{array}$ & Frey et al. $(2009,2010)$ \\
\hline 25 & OsO12 & Kinesin-14 & $\begin{array}{l}\text { Microtubule-dependent ATPase activity regulated } \\
\text { by actin }\end{array}$ & Umezu et al. (2011) \\
\hline
\end{tabular}

Only functionally characterized kinesin family members

defects in cytokinesis (Sazuka et al. 2005). OsPSS1 is essential for male meiotic chromosomal dynamics, male gametogenesis, and anther dehiscence as a kinesin-1 family member in rice (Zhou et al. 2011). KATA/ATK1, a kinesin-14 family member, is involved in chromosome segregation during microsporogenesis and microtubule accumulation in the mitotic spindle poles at early stages of spindle assembly in Arabidopsis (Chen et al. 2002;
Marcus et al. 2003). The calmodulin-binding kinesins of kinesin-14 family, such as AtKCBP, TvKCBP, and GhKCBP, function in microtubule organization or stability in interphase and mitotic cells and, consequently, in cell morphogenesis (Oppenheimer et al. 1997; Day et al. 2000; Vos et al. 2000; Preuss et al. 2003). Moreover, kinesins have redundant functions and may have synergistic roles in maintaining the organization of phragmoplast microtubules (Lee et al. 
2007). Therefore, the general function of kinesins is involved in microtubule organization mediation in mitotic process.

Plant kinesins are also involved in the cross talk of microtubules and actin microfilaments during cell growth and development, such as GhKCH1, GhKCH2, and OsKCH1 (Preuss et al. 2004; Xu et al. 2009; Frey et al. 2009, 2010). These members of the kinesin-14 family distinguish them from others by having a calponinhomology domain $(\mathrm{KCH})$ towards the $\mathrm{N}$ terminus of the polypeptide. Preuss et al. have shown that GhKCH1 interacts with actin filaments in the developing cotton fiber and plays a putative role in dynamic microtubulemicrofilament cross-linking in cotton (Gossypium hirsutum) (Preuss et al. 2004). And another $\mathrm{KCH}$ from cotton, $\mathrm{GhKCH} 2$, has been identified recently to bind actin filaments and cross-link them with microtubules in vitro (Xu et al. 2009). Most recently, the first monocotyledon member, OsKCH1, has been characterized in rice (Frey et al. 2009). OsKCH1 is associated with cortical microtubules and actin filaments both in vivo and in vitro (Frey et al. 2009). Frey et al. further show that overexpression of OsKCH1 delays nuclear positioning and mitosis in BY-2 cells. It may also be a linker between actin filaments and microtubules during nuclear positioning (Frey et al. 2010).

Besides, plant kinesins such as kinesin-13A and kinesin14 are also specifically associated with Golgi stacks or mitochondria for cell elongation. Kinesin-13A localizes to entire Golgi stacks in cotton (Lu et al. 2005) and is involved in Golgi-associated vesicles in Arabidopsis root cap cells (Wei et al. 2009). T-DNA insertion in AtKinesin-13A gene resulted in a sharp decrease of size and number of Golgi vesicles in root cap peripheral cells (Wei et al. 2009). Mutation of SRS3, member of the kinesin-13 family, causes the seed to be small and round due to cell length in the longitudinal direction in rice (Kitagawa et al. 2010). AtKP1, a plant-specific kinesin of the kinesin-14 family, binds tightly to mitochondria and specifically interacts with a mitochondrial outer-membrane protein, voltage-dependent anion channel 3 , to regulate aerobic respiration during seed germination at low temperature (Ni et al. 2005; Yang et al. 2011).

\section{Kinesin-4 exhibits diverse functions}

Structurally, kinesin-4 proteins contain a highly conserved ATPase domain at the $\mathrm{N}$ terminus and a long coiled-coil domain in the middle (stalk region), followed by a globular domain at the C terminus (Mazumdar and Misteli 2005). The ATPase domain is the "motor," providing microtubulebased mechanochemical activity; the coiled coil in the stalk region is thought to be important for protein-protein interaction, and the C-terminal domain is considered the cargo-docking domain, responsible for capturing cargos such as cytoplasmic vesicles or organelles (Mazumdar and Misteli 2005).

Kinesin- 4 proteins associate with chromosome arms, the spindle, the central spindle, and the midbody, so kinesin-4 family members function in multiple steps of cell division (Vernos et al. 1995; Goshima and Vale 2003; Kwon et al. 2004; Kurasawa et al. 2004; Mazumdar et al. 2004; Zhu et al. 2005; Zhu and Jiang 2005).

The functions of kinesin- 4 family members in plants seem to differ from those of animals. AtFRA1, the first identified plant kinesin-4 member in Arabidopsis, was involved in cellulose microfibril order (Zhong et al. 2002). The fral mutant does not show defects in cell division, and the only phenotype observed in the mutant is altered cellulose microfibril orientation in fibers of the inflorescence stems (Zhong et al. 2002). So, AtFRA1 may be directly or indirectly involved in microtubule control of cellulose microfibril order (Zhong et al. 2002). Recently, OsBC12, a homologous protein of AtFRA1 in rice, was identified by an elegant screening of fragile fiber mutants (Zhang et al. 2010). The bc12-1 mutant also shows a brittle culm phenotype, with defects in cellulose microfibril order, which is similar to its ortholog in Arabidopsis (Zhang et al. 2010). Additionally, mutation of $O s B C 12$ produced defects in cell cycle progression and cell wall composition (Zhang et al. 2010). OsBC12 is present in both the nucleus and cytoplasm and associates with microtubule arrays during cell division, which indicates that $\mathrm{OsBC} 12$ decorates some microtubule arrays during cell division and interacts with CDKA;3, probably undergoing phosphorylation for the purposes of regulation. Therefore, like other members, plant kinesin-4 proteins are involved in the cell cycle (Zhang et al. 2010).

\section{OsGDD1 with transcription factor activity is a kinesin-4 involved in regulation of the GA synthesis pathway}

The function of a protein depends on its localization in cells. AtFRA1 localizes only in cytoplasm (Zhong et al. 2002), whereas KIF4s of animals localize only in the nucleus (Wang and Adler 1995). Of interest, OsGDD1/BC12 is localized in both cytoplasm and nucleus in rice (Zhang et al. 2010; Li et al. 2011). The animal kinesin Costal2/Kif7 has an important function in transcriptional regulation by its involvement in the hedgehog signaling pathway in animals (Aikin et al. 2008; Cheung et al. 2009): derepressed Smo activates $\mathrm{Fu}$, thus leading to $\operatorname{Cos} 2 / \mathrm{Kif} 7$ phosphorylation and the release of transcriptionally active Ci155; however, this regulation is indirect. Based on the analysis of 
OsGDD1 protein sequence with a motor domain and a bZIP motif, it has been predicted and identified to have transcription factor activity in the nucleus ( $\mathrm{Li}$ et al. 2011). The function in cytoplasm and the functional shuttle between nucleus and cytoplasm need further investigation.

Similar to human KIF4A, a nuclear-localized protein, OsGDD1, has a bZIP motif (Li et al. 2011). The rice mutant gddl with suppressed cell elongation is a GA-deficient dwarf and is sensitive to GA treatment for cell elongation. OsGDD1 has microtubule and DNA binding activity, as well as transactivation activity to the target gene expression. Mutation of OsGDD1 in the 20th exon makes it lose transactivation activity. OsGDD1 in the nucleus directly regulates the transcription of $\mathrm{OSKO}_{2}$ in rice. $\mathrm{OsKO}_{2}$ is the major ent-kaurene oxidase in the gibberellin biosynthesis pathway and corresponds to D35 in rice. Mutation of D35 causes a semi-dwarf phenotype in rice (Itoh et al. 2004). Finally, endogenous GA level, as well as the mediated cortical microtubule arrangement and cell elongation, was affected in the gddl mutant (Fig. 1). Moreover, interference of stabilization maintenance of transverse cortical microtubules caused altered expression of $O_{S G D D 1}$ and $\mathrm{OSKO}_{2}$ in the rice mutant ( $\mathrm{Li}$ et al., unpublished data). This phenomenon may be due to the disorder of microtubules affecting the binding of OsGDD1 protein with microtubules in the cytoplasm and more released OsGDD1 protein getting into the nucleus and inducing the expression of OsKO2. How microtubule stability affects changes in transcription of genes such as OsGDD1 is an attractive area for further research (Fig. 1). Therefore, OsGDD1 plays an important role as a bridge for regulating microtubule stability and GA biosynthesis in rice cell growth. This is the first example of kinesins with a novel function of direct transcriptional regulation in cells.

\section{Perspectives}

Compared with kinesins in animals and fungi, plant kinesin subfamilies, such as kinesin-7 and kinesin-14, have more expanded roles. This expansion may be due to plants having unique microtubule arrays such as the preprophase band and phragmoplast, which play critical roles in plant cell division; lacking centrosomes to organize microtubules for establishing a bipolar spindle; and not producing the minus-end-directed motor dynein. Plants require novel kinesins to perform these plant-specific roles and to cover the functions performed by dyneins in animals. Hence, the expanded function of kinesins in plants may represent the need for plant-specific motors.

Plant kinesins are crucial components of the mitotic machinery; the ongoing functional characterization especially on cell growth and identification of new members will provide novel insights into their multiple aspects. In particular, the multifunctional nature of their action is an excellent opportunity to gain an integrated view of how the various kinesins are linked and coordinated with other pathways in cells. In addition to kinesins' conventional role as motors, they are emerging as important regulation components of many cell development processes. A particularly intriguing aspect of their function is their role in GA biosynthesis, and uncovering potential roles for nuclear kinesins in the interphase will be important. As well, how the kinesin OsKCH1, binding microtubules and actin, functions in the cell cycle is intriguing.

The challenge ahead is first to reveal the functions of individual kinesins. Rapidly growing resources such as pools of T-DNA and transposon insertion mutants, as well as ample collections of cDNA clones in Arabidopsis and rice, will be helpful. Then, their elaborate regulation needs elucidation, for example, where, when, and how the motor proteins are activated and what their destinations are. Finally, we need to clarify the mechanisms of coordination between kinesins and microtubules or actin microfilaments in plant cells.

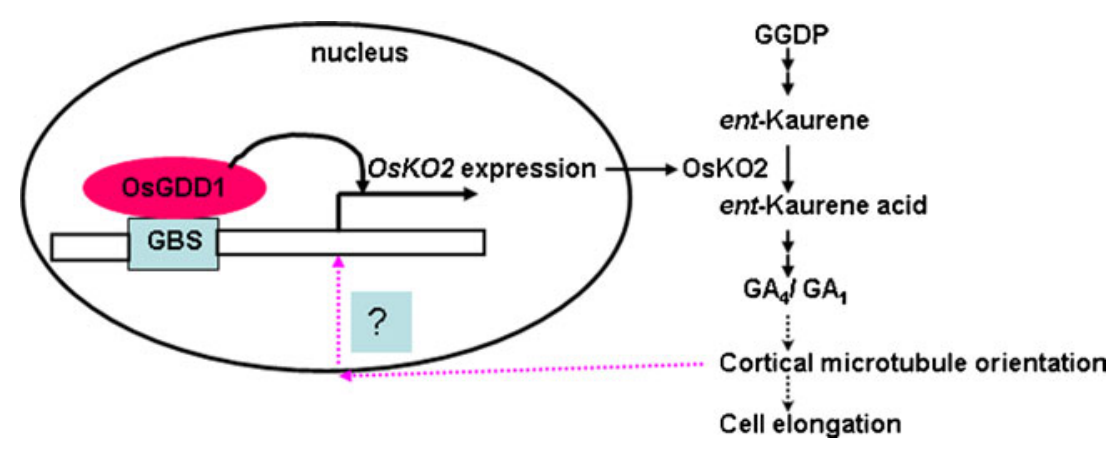

Fig. 1 Hypothetical model of OsGDD1 regulation involved in gibberellic acid biosynthesis. OsGDD1 binds to the binding site (OsGDD1 binding site, GBS) of the promoter of $\mathrm{OsKO2}$ after entering the nucleus and transactivates the expression of $\mathrm{OsKO2}$.
High expression of OsKO2 triggers the downstream GA biosynthesis pathway and accumulates active $\mathrm{GA}_{1}$ or $\mathrm{GA}_{4}$ involved in maintaining cortical microtubule orientation and cell elongation. GGDP geranylgeranyl diphosphate 
Acknowledgments This work was supported by a grant from the National Nature Science Foundation of China for Innovative Research Groups (no. 30821007).

Conflict of interest The authors declare that they have no conflict of interest.

Open Access This article is distributed under the terms of the Creative Commons Attribution Noncommercial License which permits any noncommercial use, distribution, and reproduction in any medium, provided the original author(s) and source are credited.

\section{References}

Aikin RA, Ayers KL, Therond PP (2008) The role of kinases in the Hedgehog signalling pathway. EMBO Rep 9:330-336

Bannigan A, Scheible WR, Lukowitz W, Fagerstrom C, Wadsworth P, Somerville C, Baskin TI (2007) A conserved role for kinesin-5 in plant mitosis. J Cell Sci 120:2819-2827

Bouquin T, Mattsson O, N×sted H, Foster R, Mundy J (2003) The Arabidopsis lue 1 mutant defines a katanin p60 ortholog involved in hormonal control of microtubule orientation during cell growth. J Cell Sci 116: 791-801

Chen C, Marcus A, Li W, Hu Y, Calzada JP, Grossniklaus U, Cyr RJ, Ma H (2002) The Arabidopsis ATK1 gene is required for spindle morphogenesis in male meiosis. Development 129:2401-2409

Cheung HO, Zhang X, Ribeiro A, Mo R, Makino S, Puviindran V, Law KK, Briscoe J, Hui CC (2009) The kinesin protein Kif7 is a critical regulator of Gli transcription factors in mammalian hedgehog signaling. Sci Signal 2:ra29

Day IS, Miller C, Golovkin M, Reddy AS (2000) Interaction of a kinesin-like calmodulin-binding protein with a protein kinase. J Biol Chem 275:13737-13745

Frey N, Klotz J, Nick P (2009) Dynamic bridges: a calponin-domain kinesin from rice links actin filaments and microtubules in both cycling and non-cycling cells. Plant Cell Physiol 50:1493-1506

Frey N, Klotz J, Nick P (2010) A kinesin with calponin-homology domain is involved in premitotic nuclear migration. J Exp Bot 61:3423-3437

Geelen DNV, Inze DG (2001) A bright future for the Bright Yellow-2 cell culture. Plant Physiol 127:1375-1379

Goshima G, Vale RD (2003) The roles of microtubule-based motor proteins in mitosis: comprehensive RNAi analysis in the Drosophila S2 cell line. J Cell Biol 162:1003-1016

Guo L, Ho CM, Kong Z, Lee YR, Qian Q, Liu B (2009) Evaluating the microtubule cytoskeleton and its interacting proteins in monocots by mining the rice genome. Ann Bot 103:387-402

Hirokawa N, Noda Y, Tanaka Y, Niwa S (2009) Kinesin superfamily motor proteins and intracellular transport. Nat Rev Mol Cell Biol 10:682-696

Itoh H, Tatsumi T, Sakamoto T, Otomo K, Toyomasu T, Kitano H, Ashikari M, Ichihara S, Matsuoka M (2004) A rice semi-dwarf gene, Tan-Ginbozu (D35), encodes the gibberellin biosynthesis enzyme, ent-kaurene oxidase. Plant Mol Biol 54:533-547

Kitagawa K, Kurinami S, Oki K, Abe Y, Ando T, Kono I, Yano M, Kitano H, Iwasaki Y (2010) A novel kinesin 13 protein regulating rice seed length. Plant Cell Physiol 51:1315-1329

Kong LJ, Hanley-Bowdoin L (2002) A geminivirus replication protein interacts with a protein kinase and a motor protein that display different expression patterns during plant development and infection. Plant Cell 14: 1817-1832

Kurasawa Y, Earnshaw WC, Mochizuki Y, Dohmae N, Todokoro K (2004) Essential roles of KIF4 and its binding partner PRC1 in organized central spindle midzone formation. EMBO J 23:3237-3248

Kwon M, Morales-Mulia S, Brust-Mascher I, Rogers GC, Sharp DJ, Scholey JM (2004) The chromokinesin, KLP3A, dives mitotic spindle pole separation during prometaphase and anaphase and facilitates chromatid motility. Mol Biol Cell 15:219-233

Lee YR, Liu B (2004) Cytoskeletal motors in Arabidopsis. Sixty-one kinesins and seventeen myosins. Plant Physiol 136:3877-3883

Lee YR, Li Y, Liu B (2007) Two Arabidopsis phragmoplast-associated kinesins play a critical role in cytokinesis during male gametogenesis. Plant Cell 19:2595-2605

Li J, Jiang J, Qian Q, Xu Y, Zhang C, Xiao J, Du C, Luo W, Zou G, Chen M, Huang Y, Feng Y, Cheng Z, Yuan M, Chong K (2011) Mutation of rice $\mathrm{BC} 12 / \mathrm{GDD} 1$, which encodes a kinesin-like protein that binds to a GA biosynthesis gene promoter, leads to dwarfism with impaired cell elongation. Plant Cell 23:628-640

Lu L, Lee YR, Pan R, Maloof JN, Liu B (2005) An internal motor kinesin is associated with the Golgi apparatus and plays a role in trichome morphogenesis in Arabidopsis. Mol Biol Cell 16:811-823

Marcus AI, Li W, Ma H, Cyr RJ (2003) A kinesin mutant with an atypical bipolar spindle undergoes normal mitosis. Mol Biol Cell 14:1717-1726

Mazumdar M, Misteli T (2005) Chromokinesins: multitalented players in mitosis. Trends Cell Biol 15:349-355

Mazumdar M, Sundareshan S, Misteli T (2004) Human chromokinesin KIF4A functions in chromosome condensation and segregation. $\mathrm{J}$ Cell Biol 166:613-620

Ni CZ, Wang HQ, Xu T, Qu Z, Liu GQ (2005) AtKP1, a kinesin-like protein, mainly localizes to mitochondria in Arabidopsis thaliana. Cell Res 15:725-733

Nishihama R, Soyano T, Ishikawa M, Araki S, Tanaka H, Asada T, Irie K, Ito M, Terada M, Banno H, Yamazaki Y, Machida Y (2002) Expansion of the cell plate in plant cytokinesis requires a kinesin-like protein/MAPKKK complex. Cell 109:87-99

Oppenheimer DG, Pollock MA, Vacik J, Szymanski DB, Ericson B, Feldmann K, Marks MD (1997) Essential role of a kinesin-like protein in Arabidopsis trichome morphogenesis. Proc Natl Acad Sci USA 94:6261-6266

Preuss ML, Delmer DP, Liu B (2003) The cotton kinesin-like calmodulin-binding protein associates with cortical microtubules in cotton fibers. Plant Physiol 132:154-160

Preuss ML, Kovar DR, Lee YR, Staiger CJ, Delmer DP, Liu B (2004) A plant-specific kinesin binds to actin microfilaments and interacts with cortical microtubules in cotton fibers. Plant Physiol 136:3945-3955

Reddy AS, Day IS (2001) Kinesins in the Arabidopsis genome: a comparative analysis among eukaryotes. BMC Genomics 2:2

Reddy AS, Narasimhulu SB, Safadi F, Golovkin M (1996) A plant kinesin heavy chain-like protein is a calmodulin-binding protein. Plant J 10:9-21

Richardson DN, Simmons MP, Reddy AS (2006) Comprehensive comparative analysis of kinesins in photosynthetic eukaryotes. BMC Genomics 7:18

Sazuka T, Aichi I, Kawai T, Matsuo N, Kitano H, Matsuoka M (2005) The rice mutant dwarf bamboo shoot 1: a leaky mutant of the NACK-type kinesin-like gene can initiate organ primordia but not organ development. Plant Cell Physiol 46:1934-1943

Sharp DJ, Brown HM, Kwon M, Rogers GC, Holland G, Scholey JM (2000) Functional coordination of three mitotic motors in Drosophila embryos. Mol Biol Cell 11:241-253

Song H, Golovkin M, Reddy ASN, Endow SA (1997) In vitro motility of AtKCBP, a calmodulin-binding kinesin-like protein of Arabidopsis. Proc Natl Acad Sci USA 94: 322-327 
Strompen G, El Kasmi F, Richter S, Lukowitz W, Assaad FF, Jurgens G, Mayer U (2002) The Arabidopsis HINKEL gene encodes a kinesin-related protein involved in cytokinesis and is expressed in a cell cycle-dependent manner. Curr Biol 12:153-158

Suetsugu N, Yamada N, Kagawa T, Yonekura H, Uyeda T, Kadota A, Wada M (2010) Two kinesin-like proteins mediate actin-based chloroplast movement in Arabidopsis thaliana. Proc Natl Acad Sci USA 107: 8860-8865

Umezu N, Umeki N, Mitsui T, Kondo K, Maruta S (2011) Characterization of a novel rice kinesin $\mathrm{O} 12$ with a calponin homology domain. J Biochem 149(1):91-101.

Vale RD (2003) The molecular motor toolbox for intracellular transport. Cell 112:467-480

Vanstraelen M, Acosta JAT, Veylder LD, InzÅ D, Geelen D (2004) A plant-specific subclass of C-terminal kinesins contains a conserved A-type cyclin-dependent kinase site implicated in folding anddimerization. Plant Physiol 135: 1417-1429

Verhey KJ, Meyer D, Deehan R, Blenis J, Schnapp BJ, Rapoport TA, Margolis B (2001) Cargo of kinesin identified as JIP scaffolding proteins and associated signaling molecules. J Cell Biol 152:959970

Vernos I, Raats J, Hirano T, Heasman J, Karsenti E, Wylie C (1995) Xklp1, a chromosomal Xenopus kinesin-like protein essential for spindle organization and chromosome positioning. Cell $81: 117-127$

Vos JW, Safadi F, Reddy AS, Hepler PK (2000) The kinesin-like calmodulin binding protein is differentially involved in cell division. Plant Cell 12:979-990

Wang SZ, Adler R (1995) Chromokinesin: a DNA-binding, kinesin-like nuclear protein. J Cell Biol 128:761-768

Wei L, Zhang W, Liu Z, Li Y (2009) AtKinesin-13A is located on Golgi-associated vesicle and involved in vesicle formation/ budding in Arabidopsis root-cap peripheral cells. BMC Plant Biol 9:138

Xu T, Qu Z, Yang X, Qin X, Xiong J, Wang Y, Ren D, Liu G (2009) A cotton kinesin GhKCH2 interacts with both microtubules and microfilaments. Biochem J 421:171-180

Yang CY, Spielman M, Coles JP, Li Y, Ghelani S, Bourdon V, Brown RC, Lemmon BE, Scott RJ, Dickinson HG (2003) TETRASPORE encodes a kinesin required for male meiotic cytokinesis in Arabidopsis. Plant J 34:229-240

Yang XY, Chen ZW, Xu T, Qu Z, Pan XD, Qin XH, Ren DT, Liu GQ (2011) Arabidopsis kinesin KP1 specifically interacts with VDAC3, a mitochondrial protein, and regulates respiration during seed germination at low temperature. Plant Cell 23:1093-1106

Zhang M, Zhang B, Qian Q, Yu Y, Li R, Zhang J, Liu X, Zeng D, Li J, Zhou Y (2010) Brittle Culm 12, a dual-targeting kinesin-4 protein, controls cell-cycle progression and wall properties in rice. Plant J 63:312-328

Zhong R, Burk DH, Morrison WH 3rd, Ye ZH (2002) A kinesin-like protein is essential for oriented deposition of cellulose microfibrils and cell wall strength. Plant Cell 14:3101-3117

Zhou S, Wang Y, Li W, Zhao Z, Ren Y, Wang Y, Gu S, Lin Q, Wang D, Jiang L, Su N, Zhang X, Liu L, Cheng Z, Lei C, Wang J, Guo X, Wu F, Ikehashi H, Wang H, Wan J (2011) Pollen semi-sterility1 encodes a kinesin-1-like protein important for male meiosis, anther dehiscence, and fertility in rice. Plant Cell 23:111-129

Zhu C, Jiang W (2005) Cell cycle-dependent translocation of PRC1 on the spindle by Kif4 is essential for midzone formation and cytokinesis. Proc Natl Acad Sci USA 102:343-348

Zhu C, Zhao J, Bibikova M, Leverson JD, Bossy-Wetzel E, Fan JB, Abraham RT, Jiang W (2005) Functional analysis of human microtubule-based motor proteins, the kinesins and dyneins, in mitosis/cytokinesis using RNA interference. Mol Biol Cell 16:3187-3199 